\title{
Reduction of cardio-metabolic risk by diet, cereal betaglucan fibre drink and Bellylatinofit dance program
}

\author{
L. Mikušová ${ }^{1}$, A. Holubková ${ }^{1}$, M. Valachovičová2 ${ }^{2}$ I. Kajaba ${ }^{2}$, M. Bobrík ${ }^{3}$ and E. Šturdík ${ }^{1}$ \\ ${ }^{1}$ Institute of Biochemistry, Nutrition and Health Protection, Slovak University of Technology, ${ }^{2}$ Slovak Medical University, \\ Slovak Republic and ${ }^{3}$ Department of Physical Education and Sport, Slovak University of Technology, Slovak Republic
}

Lifestyle interventions such as nutritionally balanced diet, physical activity and weight management are generally recommended to reduce the risk of civilisation diseases such as obesity, diabetes, cardiovascular diseases or metabolic syndrome ${ }^{(1)}$. Moreover, consumption of fibre rich food containing betaglucans and regular exercise are known to lower the total and LDL cholesterol levels ${ }^{(1,2)}$. Hence dance exercise has not been evaluated yet in combination with betaglucan fibre supplementation; the aim of this study was to investigate the effect of the two month long intervention consisting of nutritionally balanced diet, Actiglucane fibre drink consumption and regular dance exercise.

Fifteen non-smoking healthy women with higher body fat percentage $(\geq 29 \%)$ in the age $19-34$ years $\left(\mathrm{BMI} 26.6 \mathrm{~kg} / \mathrm{cm}^{2}\right.$, SE: $0.9 \mathrm{~kg} / \mathrm{cm}^{2}$; body weight $77.2 \mathrm{~kg}, \mathrm{SE}: 3.5 \mathrm{~kg}$; waist circumference $87.3 \mathrm{~cm}$, sE: $2.6 \mathrm{~cm}$; total cholesterol $5.61 \mathrm{mmol} / 1, \mathrm{sE}: 0.40 \mathrm{mmol} / \mathrm{l}$ ) and ten matching controls were recruited to participate in the study. Subjects in the intervention group underwent dietary counselling every 2 weeks during two months prior to the study (adaptation period) and during the study itself. They were encouraged to lower consumption of high energy and high fat food, to enhance consumption of fruit and vegetables, as well as to control their daily portions (frequency and size) to achieve nutritionally balanced diet. Food diaries were collected weekly via emails and were studied using Alimenta nutrition software (Food Research Institute, Bratislava). At the beginning of the study, Actiglucane fibre drink (3g of $\beta$-glucan/ day) was implemented into their diet. Participants attended 3-times a week 75 minute long dance classes with moderate intensity. Blood samples for biochemical analysis were drawn from antecubital vein, analysis of body composition using In Body Analyser and Eurofit Physique and Motor Fitness tests were done at the beginning and at the end of the study ( 2 months). One-way ANOVA was used for each parameter to test the statistical significance.

Nutritionally balanced diet and Bellylatinofit dance program itself (adaptation period) did not cause any significant changes in antropometric and biochemical parameters, as well as Bellylatinofit dance program without diet intervention (control group). However, significant reduction in total cholesterol $(0.42 \mathrm{mmol} / \mathrm{l} ; \mathrm{sE}: 0.1 \mathrm{mmol} / \mathrm{l} ; P<0.05)$, LDL cholesterol $(0.40 \mathrm{mmol} / \mathrm{l} ; \mathrm{sE}: 0.1 \mathrm{mmol} / \mathrm{l} ; P<0.05)$, atherogenic index $(0.63$; SE: $0.19 ; P<0.01)$, body fat mass $(2.5 \mathrm{~kg} ; \mathrm{SE}: 0.4 \mathrm{~kg} ; P<0.05)$, BMI $\left(0.88 \mathrm{~kg} / \mathrm{cm}^{2} ; \mathrm{SE}: 0.16 \mathrm{~kg} / \mathrm{cm}^{2} ; P<0.01\right)$ and waist to hip ratio $(0.011$; SE: $0.003 ; P<0.05)$ was achieved throughout the 2 month long intervention (combination of nutritionally balanced diet, Actiglucane and Bellylatinofit dance program). Moreover, Bellylatinofit dance program improved coordination, strength, flexibility and general fitness level of all participants. Owing to these beneficial effects, the program may be used as a preventive strategy at a larger population scale.

The work was supported by the Slovak Research and Development Agency under the contract No. VMSP-II-0024-09 and the Agency of the Ministry of Education, Science, Research and Sport of the Slovak Republic for the Structural Funds of EU, Project No. ITMS 26240220040.

1. Vuori IM (2001) Publ Health Nutr 4(2B): 517-528.

2. Tiwari U \& Cummins E (2011) Nutr 27, 1008-1016. 